\title{
Emergency management and resuscitation of poisoned patients: perspectives from "down under" Mark Little ${ }^{1,2}$
}

Address: ${ }^{1}$ Royal Perth Hospital, Welllington St, Perth, Western Australia, Australia and ${ }^{2}$ University of Western Australia, Crawley WA 6009, Perth, Australia

Email: Mark Little - mark.little@health.wa.gov.au

Published: 23 August 2009

Scandinavian Journal of Trauma, Resuscitation and Emergency Medicine 2009, 17:36 doi:10.1 186/1757-7241-17-36
Received: 8 July 2009

Accepted: 23 August 2009

This article is available from: http://www.sjtrem.com/content//7/I/36

(c) 2009 Little; licensee BioMed Central Ltd.

This is an Open Access article distributed under the terms of the Creative Commons Attribution License (http://creativecommons.org/licenses/by/2.0), which permits unrestricted use, distribution, and reproduction in any medium, provided the original work is properly cited.

\section{Introduction}

Deliberate self poisoning (DSP) is a common presentation to an emergency department (ED), being an acute medical exacerbation of a chronic psychosocial disorder [1]. At Sir Charles Gairdner Hospital (SCGH) in Perth Western Australia, DSP and intoxication accounts for $4.6 \%$ of all ED presentations [2], the Austin Hospital in Melbourne, reported 650 presentations per year $(2 \%$ of their ED presentations) [3]. In the UK, Kappur estimated an annual rate of presentation to a UK hospital of 310/ 100000 population and estimated 170000 presentations to EDs in the UK [4]. One American study estimated an annual rate of ED presentation of self harm in $7-24$ years old at 225.3 per 100000 population [5].

With such a caseload it is important that there is a structured process to the management and disposition of cases, as Boyle and her colleagues have described in their review article on the management of the critically poisoned patient [6]. As Boyle discussed resuscitation is an essential part of the management of the poisoned patient, and often this and good supportive care is all that is required in the patients management.

\section{Indications for intubation}

The decision to intubate a poisoned patient with a Glasgow Coma Score (GCS) of 9-13 remains a difficult dilemma. In an Australian study of over 4500 overdose admissions there was a prolonged increase in ICU length of stay for a patient with aspiration ( $126 \mathrm{hrs}$ for those who aspirated vs 14.7 hrs for those who did not) and death ( $8.5 \%$ vs $0.4 \%)$ [7]. I therefore advocate early intubation with DSP in patients developing a reduced LOC

Controversies in cardiopulmonary resuscitation Cardiac arrest in a poisoned patient is another area where the toxicological management will be different to standard ED protocols. Most cardiac arrests in adult ED's are due to ischaemic heart disease and usually there is poor success after a period of time (eg $30-60 \mathrm{~m}$ ) of resuscitation. In a poisoned patient, patients are often young and if they are supported through this period they will totally recover. I advocate prolonged CPR (my colleague teaches our junior staff to continue until at least the end of their shift!) and there may be roles for antidotes (such as a digoxin fragment antibody, bicarbonate and high dose insulin) and heroic measures such as cardiopulmonary bypass. For example, in a series of 56 cardiac arrests due to digoxin toxicity the survival with the use of digoxin fragment antibody was $54 \%$, making it the most successful intervention in cardiac arrest [8]. Mortality prior to the use of digoxin fragment antibody was $100 \%$. In the 2005 American Heart Association Guidelines for cardiopulmonary resuscitation and emergency cardiovascular care, there is a separate section specifically on toxicology in emergency cardiovascular care [9], which many clinicians may be unaware of. 


\section{Management issues}

In Australia, after resuscitation, our approach is to then perform a risk assessment to identify the severity (or otherwise) of the poisoning based on a variety of factors included the agent and dose ingested, the time since ingestion, symptoms and signs exhibited and any premorbid factors. This risk assessment would dictate further management [1].

As Boyle has described there are many issues to be considered [6]. Hyperthermia is an important sign not to be missed. In Australia due to the increased usage the increased availability of serotonergically active drugs (including amphetamines) we are commonly seeing serotonin syndrome in our patients, this being a clinical diagnosis. Lower limb clonus is highly suggestive of the diagnosis [10], and its diagnosis and management is well detailed by Boyle's article.

\section{Toxicology in Australia}

In Australian there has been the establishment of toxicology services managing poisoned patients. In Perth, the Western Australian Toxicology Service (WATS) runs an emergency department based toxicology service across three tertiary hospitals. Emergency Physicians with 2 year subspecialty training in toxicology admit patients directly under their care to the intensive care unit or the emergency observation unit (EOU). Working closely with psychiatric, drug and alcohol and social worker services care is provided in parallel with poisoned patients in both the ICU and EOU $[1,2,11]$. Patients are returned to the EOU as soon as a patient is cleared from the ICU. In 2005 SCGH (one of the three hospitals) had 1859 DSP presentations and 1010 admission with 85 ICU admissions. The average length of stay was 12 hours. In the first 12 months of establishing a toxicology service in Melbourne, Lee et demonstrated a significant reduction in length of stay for poisoned patients admitted to their service. Length of stay (LOS) for uncomplicated admissions dropped from 1.97 days to 1.4 days, and for complicated admissions the LOS dropped from 5.59 days to 1.92 days [3].

In Perth, our commonest toxicological presentation is an overdose due to alcohol and benzodiazepines. Other commonly overdosed agents are the SSRI and SNRI's, atypical antipsychotics, inparticularly quetiapine and paracetomol (although we would use $\mathrm{N}$ acetyl cysteine only once a fortnight). Quetiapine would be our commonest agent causing coma requiring ventilation and admission to the ICU. Until the last 6 months presentations due to amphetamine intoxication was about $1 \%$ of all ED presentations to Royal Perth Hospital, but in recent times opiate overdoses have increased. Tricyclic antidepressant overdoses are rarely seen nowadays in Perth.

\section{Envenomings}

Contrary to the public perceptions, snakebite is rarely seen. We would admit about 5 envenomed patients per year to Royal Perth Hospital, although many other non envenomed snakebites are seen. Around Perth the most common envenoming is due to the dugite snake (Pseudonaja affinis) and patients present with a venom induced consumptive coagulopathy. Occasionally these patients have sudden cardiovascular collapse, but often they present with non specific symptoms and incoagulable blood. Earlier this year one of our patients died from an intracerebral haemorrhage, however death is rare. There is a monovalent antivenom that we use to treat these patients. In recent times we have described a rare complication of microangiopathic haemolytic anaemia (MAHA) developing after envenoming by snakes of the Pseudonaja genus [12]. Even if these patients are envenomed, unless they require ventilation, all are managed in our EOU.

More commonly during summer, we manage many patients envenomed by the red back spider (Lactrodectus hasselti). We have one of the highest incidences in the world of the syndrome of lactrodectism. Patients present with significant bite site pain or systemic features of generalised pain, autonomic features including sweating hypertension and tachycardia. No deaths have occurred in Australia since the antivenom was introduced in the 1950's, and in Australia more red back spider antivenom is administered than all the other snake, spider, stonefish, box jellyfish antivenoms available.

\section{Toxicology network in Australia}

In Australia we have a Poisons Information Centre (PIC) network that utilises one national phone number. There are PICs in Perth, Sydney, Brisbane and Melbourne and we have a system so that one centre (usually NSW) takes all national calls overnight. In 2008, there were over 235 000 calls to this network [11]. Paracetomol calls remain the commonest call referred to clinical toxicologists. In Australia clinical toxicology is a new speciality there are about 20 clinical toxicologists and 6 fellows training. There are a number of emergency medicine trainees with 6 month accredited training posts in clinical toxicology. As well as running clinical toxicology services around the country, clinical toxicologists provide back up to the PIC network, and meet 5 times a year in Sydney to discuss interesting cases and management issues. All calls taken by the clinical toxicologists are peer reviewed by having calls emailed to all PIC staff. Locally WATS meets each week, reviewing cases and leading teaching sessions for emergency medicine staff at a number of hospitals in Perth. We have also published Australasia's first textbook in clinical toxicology which is being used at most Emergency departments around the country [13]. 


\section{Conclusion}

In conclusion, DSP is a common presentation to an ED. Boyle and her colleagues are to be commended for their article detailing a structured approach to the poisoned patient. In my service, the use of the EOU in the care of the poisoned patient had dramatically improved care and reduced length of stay. With a structured approach to these patients and dedicated toxicology units for these patients I believe quality care will improve.

\section{Competing interests}

The author declares that they have no competing interests.

\section{References}

I. Daly FFS, Little M, Murray L: A risk assessment based approach to the management of acute poisoning. Emerg Med J 2006, 23:396-9.

2. Daly FFS, Murray LM, Little M, Dart RC: Specialised centres for the treatment of poisoned patients. In Medical Toxicology 3rd edition. Edited by: Dart RC. Philidelphia, USA: Lippincott Williams \& Wilkins; 2004.

3. Lee V, Kerr JF, Braitberg G, Louis WJ, O'Callaghan CJ, Frauman AG, Mashford ML: Impact of a toxicology service on a metropolitan teaching hospital. Emerg Med 200I, I3:37-42.

4. Kapur N, House A, Creed F, Feldman E, Friedman T, Guthrie E: Management of deliberate self poisoning in adults in four teaching hospitals: descriptive study. BMJ 1998, 316:83I-2.

5. Olfson M, Gameroff MJ, Marcus SC, Greenberg T, Shaffer D: Emergency treatment of young people following deliberate selfharm. Arch Gen psychiatry 2005, 62: I I22-8.

6. Boyle JS, Bechtel LK, Holstege CP: Management of the critically poisoned patient. Scand J Trauma Resusc Emerg Med 2009, I 7(I):29.

7. Isbister GK, Downes F, Sibbritt D, Dawson AH, Whyte IM: Aspiration pneumonitis in an overdose population: frequency, predictors, and outcomes. Crit Care Med 2004, 32:88-93.

8. Antman EM, Wenger TL, Butler VP Jr, Haber E, Smith TW: Treatment of 150 cases of life-threatening digitalis intoxication with digoxin-specific Fab antibody fragments. Final report of a multicenter study. Circulation 1990, 81 : 1744-52.

9. The American Heart Association Guidelines for Cardiopulmonary Resuscitation and Emergency Cardiovascular Care: I 0.2 Toxicology in ECC. Circulation 2005, I I 2:IV I26-IV I32.

10. Isbister GK, Buckley NA, Whyte IM: Serotonin toxicity: a practical approach to diagnosis and management. Med J Aust 2007 187:361-365.

II. New South Wales Poisons Information Centre 2008 Annual Report [http://www.chw.edu.au/poisons/]

12. Isbister GK, Little M, Cull G, McCoubrie D, Lawton P, Szabo F, Kennedy J, Trethewy C, Luxton G, Brown SG, Currie BJ: Thrombotic microangiopathy from Australian brown snake (Pseudonaja) envenoming. Int Med J 2007, 37:523-8.

13. Murray L, Daly F, Little M, Cadogan M: Toxicology handbook. Sydney: Elsevier Australia, Churchill Livingstone; 2007.

Publish with Bio Med Central and every scientist can read your work free of charge

"BioMed Central will be the most significant development for disseminating the results of biomedical research in our lifetime. "

Sir Paul Nurse, Cancer Research UK

Your research papers will be:

- available free of charge to the entire biomedical community

- peer reviewed and published immediately upon acceptance

- cited in PubMed and archived on PubMed Central

- yours - you keep the copyright
BioMedcentral 